\title{
Excavation and Conveying Technologies for Space Applications
}

\author{
Dominik Höber ${ }^{1}$, Andreas Taschner ${ }^{1}$, and Eric Fimbinger ${ }^{2}$ \\ ${ }^{1}$ Mechanical Engineering studies programme, Montanuniversität Leoben, Leoben, Austria \\ ${ }^{2}$ Chair of Mining Engineering - Conveying Technology and Design Methods, Montanuniversität Leoben, Leoben, \\ Austria
}

Received December 2, 2020; accepted December 15, 2020; published online January 14, 2021

\begin{abstract}
A rising number of companies and organisations are researching space technologies supporting extraterrestrial life. Whether Moon or Mars, the number of rocket launches is increasing year by year. The majority of $\mathrm{Na}$ tional Space Agencies are planning exploration missions with fully autonomous robots, which can conduct several studies about the composition of the lunar dust. Especially the extraction of oxygen from the moon dust, called regolith, is of great interest. Also many other projects are planned. But the initial step of all processes is often forgotten: it is the supply of raw materials. Therefore, a closer look at the possibilities of excavating and conveying regolith has been taken. The research ranges from concept development, calculation to simulation and designing a robotic system.
\end{abstract}

Keywords: Space mining, Space conveying, ISRU, Regolith

Abbau- und Fördertechnologien für Weltraumanwendungen

Zusammenfassung: Zahlreiche Unternehmen sowie Organisationen beschäftigen sich mit der Forschung auf dem Gebiet der Weltraumtechnologien, um ein Leben abseits der Erde zu ermöglichen. Egal ob Mond oder Mars, die Anzahl der Raketenstarts mit diesen Zielen steigen kontinuierlich. Der Großteil der geplanten Missionen besteht aus Erkundungsmissionen mit vollautonomen Robotern, welches das Ziel verfolgen, die Mondzusammensetzung zu erforschen. Für die weitere Verwendung von Mondstaub, auch Regolith genannt, ist die Gewinnung von Sauerstoff am at-

D. Höber, BSc $(\bowtie) \cdot A$. Taschner, BSc $(\varangle)$

Mechanical Engineering studies programme,

Montanuniversität Leoben,

Franz-Josef-Straße 18,

8700 Leoben, Austria

dominik.hoeber@stud.unileoben.ac.at;

andreas.taschner@stud.unileoben.ac.at traktivsten. Doch auch viele weitere Projekte stehen bereits in den Startlöchern. Bei den vielen Ideen wird oft auf den grundlegensten Schritt vergessen: der Bereitstellung von Roh- bzw. Grundmaterialien. Deswegen werden die Möglichkeiten des Abbaus sowie der Förderung von Regolith im Rahmen zweier Forschungsarbeiten untersucht. Diese Forschung reicht von der Konzeptfindung und Berechnung bis hin zu Simulation und Konstruktion eines geeigneten Robotersystems.

Schlüsselwörter: Weltraumbergbau, Fördertechnik im Weltraum, Ressourcennutzung vor Ort, Regolith

\section{Introduction}

The space-age began approximately in the third quarter of the last century. The most historic and important milestone was the moon landing in 1969. With his words: “That's one small step for a man, one giant leap for mankind", Neil Armstrong and his crew inspired people all over the world. Now, this enthusiasm has increased sharply again in the last few years. This reawakened interest is especially due to some large corporations that have entered the private aerospace sector, also for space activities. For example, Jeff Bezos and Elon Musk founded their own space companies, which are offering delivery or by now even crewed flights into space. As a result of this evolution and the resulting kind of competition, it is interesting for various organisations, also including space-pioneer NASA (National Aeronautics and Space Organisation) for example, to outsource the transport into space to such companies.

Currently, the Moon enjoys special attention because of its constellation in relation to Earth, and due to some specific characteristics, especially related to lunar regolith, which offers many possibilities. At the moment, the main goal of most organisations is the extraction of oxygen out of this regolith. There are two leading purposes for this oxygen: on the one hand, to make life on the Moon pos- 
sible, and on the other hand, to produce fuel for rockets. The Moon has a thin atmosphere and a low gravity, which means that greater distances could be covered with less fuel if a rocket started from the lunar surface. But before this is realisable, several steps are necessary. While the research on lunar regolith and the extraction of oxygen is already in progress, the development of various kinds of extraterrestrial mining machines is still at the beginning.

\section{Personal Motivation}

For many engineers, space exploration is a big dream because space engineers are pioneers in developing new technologies. At the beginning of our studies, we did not think a lot about the possibility to work and do research in this area, but through the NASA Bucket Drum Excavation Challenge, we recognised the potential in excavating lunar regolith. Therefore, we wanted to contribute to the possibilities of excavating and conveying in space applications, within the context of a master's thesis, and are glad to have found an excellent mentor in Professor Sifferlinger and his team at the Chair of Mining Engineering, Montanuniversität Leoben. We then divided the task areas into one mining part and one conveying part. Currently, we are in the middle of our work and are proud to present our first partial results in the course of this article.

\section{Moon Environment}

The Moon is the celestial body closest to Earth. It has a diameter of $3476 \mathrm{~km}$ and a mass of about $0.7 \times 10^{23} \mathrm{~kg}$. The distance from Earth to the Moon is about $400,000 \mathrm{~km}$ (Fig. 1). Some specific characteristics are, for example, low gravity, high-temperature fluctuations, and a thin atmosphere [2].

Gravity: The total mass and the radius of the Moon are parameters for gravitational acceleration. Consequently, the gravitational acceleration on the Moon is about $1.622 \mathrm{~m} / \mathrm{s}^{2}$, which is only a sixth compared to Earth. For instance, if there is a person with $90 \mathrm{~kg}$ on Earth, he/she has only $15 \mathrm{~kg}$ on the Moon [3].

Temperature fluctuations, the temperature range extends from $-258^{\circ} \mathrm{C}$ (at the poles) to $127^{\circ} \mathrm{C}$ (at the equator). As can be seen in Fig. 2, there are big temperature differences between night and day. The figure shows the temperature on the lunar surface and also the nearly constant temperature one meter under the surface. One Lunation (a day on the Moon) is $709 \mathrm{~h}$ long, which equals about 29.5 earth-days [2].

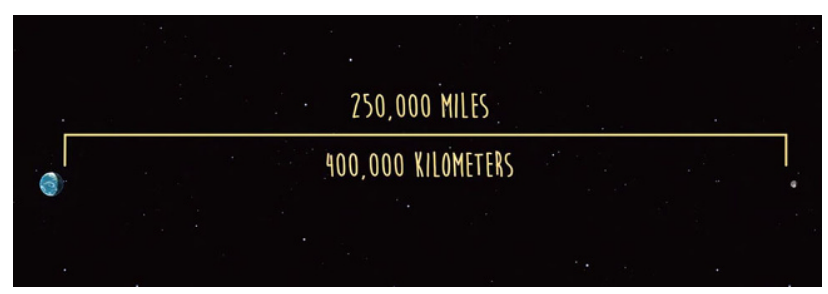

Fig. 1: Distance between Earth and the Moon [1]

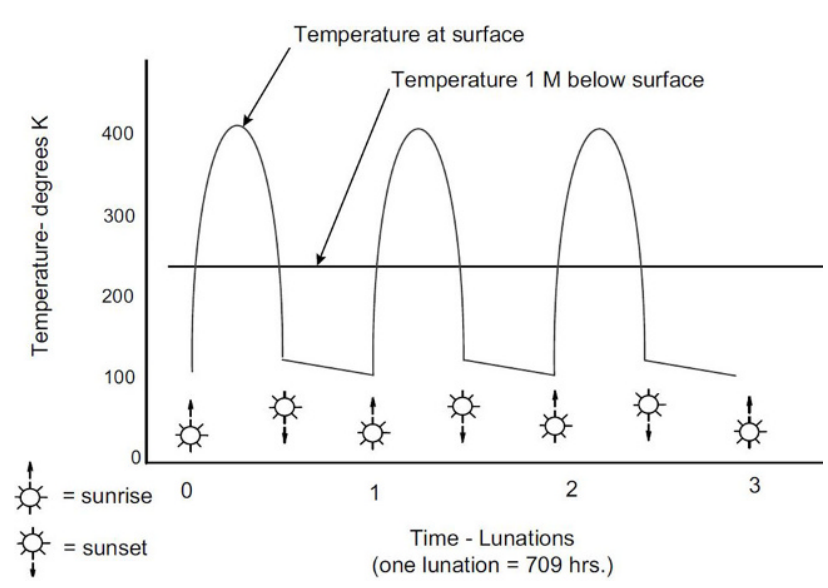

Fig. 2: Temperature fluctuations within lunar days [2]

Atmosphere: With a gas concentration of about $2 \times 10^{5}$ molecules per cubic centimetre, the atmosphere is much thinner than on Earth (14 times). The atmosphere consists of different gases like neon, helium, hydrogen, argon, methane, carbon dioxide, ammonia, and hydroxide. The concentration differs depending on daytime and night time [4].

lonising radiation: In the lunar environment, there are three types of radiation, which all have different effects. These are the solar wind, the solar cosmic rays, and the galactic cosmic rays. Because of this radiation, humans would have to use protections like shields when they are on the lunar surface [4].

\section{Regolith}

There are several materials on the Moon, but for the desired application of extracting oxygen from the lunar surface, only regolith is important to the present research project. Regolith is the material of the lunar soil and results from meteorite impacts (mostly micrometeorites). The thickness of this layer measures about four to fifteen meters [2].

Elements: Regolith consists of many raw elements that are bound in the form of oxides. Due to that, the most frequent element is oxygen, followed by silicon and aluminium. Regolith also contains some parts of calcium, magnesium, iron, sodium, and titanium. There are also trace elements in the lunar soil, like sulfur, phosphorus, carbon, hydrogen, nitrogen, helium, and neon [2].

Properties: The bulk density of surface regolith is about 1.45 to $1.71 \mathrm{~g} / \mathrm{cm}^{3}$ and depends on the depth (Table 1). This difference was measured already in the first $60 \mathrm{~cm}$. The lunar soil consists of grains with a size from 20 to $500 \mu \mathrm{m}$ with the following distribution and classification:

- $20-45 \mu \mathrm{m}: 17.37 \%$

- $45-75 \mu \mathrm{m}: 14.45 \%$

- $75-90 \mu \mathrm{m}: 5.48 \%$

- $90-150 \mu \mathrm{m}: 15.99 \%$

- $150-250 \mu \mathrm{m}: 13.13 \%$

- $250-500 \mu \mathrm{m}: 11.91 \%$ 


\begin{tabular}{|llll|}
\hline $\begin{array}{l}\text { TABLE } 1 \\
\text { Regolith properties }[4,5]\end{array}$ & & \\
\hline Depth & Cohesion $(\mathrm{kPa})$ & Internal friction angle $\left(^{\circ}\right)$ & Bulk density $\left(\mathrm{g} / \mathrm{cm}^{3}\right)$ \\
\hline $0-15 \mathrm{~cm}$ & 0.52 & 42 & $1.45-1.55$ \\
\hline $0-30 \mathrm{~cm}$ & 0.9 & 46 & $1.53-1.63$ \\
\hline $30-60 \mathrm{~cm}$ & 3.0 & 54 & $1.69-1.79$ \\
\hline $0-60 \mathrm{~cm}$ & 1.6 & 49.5 & $1.61-1.71$ \\
\hline
\end{tabular}

The rest up to $100 \%(21.77 \%)$ are undefined and therefore not assigned further. Here it is categorised as dust. There are some bigger parts like rocks, but these are not of interest for the normal grain size distribution. Another important property is the grain form. Due to the high temperature created by the meteorite impact, there is also glass in the grain. Because of this glass portion, there are grains called agglutinates, which are very sharp and can lead to higher wear for machines handling this material. Fig. 3 shows an agglutinate [4-6].

Behaviour: As Table 1 shows, regolith has high cohesion, especially in the deeper places, so there the grains may clump together. Also the internal friction angle, which is a parameter for the inner friction, increases with the depth. With regards to the Apollo missions, the lunar dust, with its particles less than $20 \mu \mathrm{m}$ in diameter, is a serious problem. Moondust is electrostatically attracted to surfaces and is difficult to remove. The mobility of lunar rovers is also badly affected by the lunar dust because it sticks to the wheels. As a result, the lunar rovers have less traction [2, 4-6].

\section{In Situ Resource Utilization (ISRU)}

In Situ Resource Utilization (ISRU) is defined as follows: "In-Situ Resource Utilization is the collection, processing, and use of materials encountered in the course of human or robotic space exploration that replace materials that would

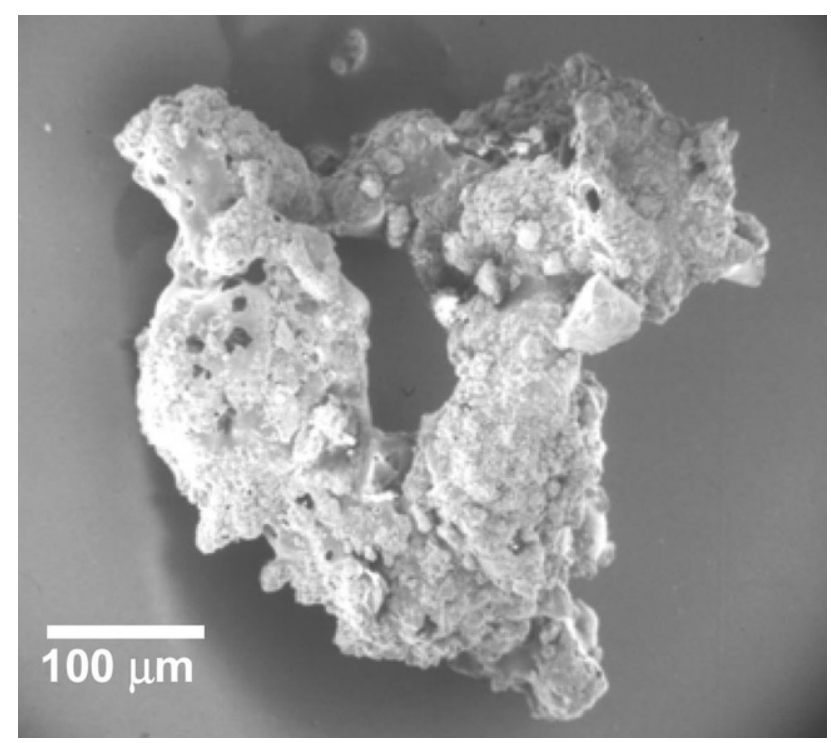

Fig. 3: Agglutinate [2] otherwise be brought from Earth to accomplish a missioncritical need at reduced overall coast and risk" [7].

While ISRU includes every planet and celestial body on which ISRU is possible, ISRU in this section is only considered for the Moon and lunar missions. Native resources like regolith are used as raw materials for the production of essential products and goods for a human being on the Moon. For example, the production of spare and wear parts, life support gases, propellants, and building infrastructure is included in ISRU. One aim of ISRU is to use raw materials existing on the Moon instead of transporting everything from Earth to the Moon. As a consequence, the reduced logistics from Earth to the Moon leads to lower costs. Moreover, long-term missions are enabled with ISRU, like lunar soil excavations, where the provision of energy is necessary. A major difficulty is the multidisciplinarity of ISRU. For a functioning ISRU chain, shown in Fig. 4, all links must be coordinated. The main links of an ISRU chain are excavation, material handling, beneficiation, and processing $[2$, 7, 8].

Excavation: The majority of excavators on Earth are designed for big excavation forces without a loss of traction. The tractive force depends on the gravitational acceleration and the mass of the excavator. Consequently, terrestrial excavators are heavyweight solutions. Lunar excavators should be designed for low excavation forces and with low mass as the delivery of a large payload leads to high financial costs [9].

Material handling: The next step after the excavation of regolith is the transportation of the raw material to the production plant. There are two main tasks: the transportation of regolith from the excavator to the production plant and the conveyance within the production plant between the different steps of processing. The distance of delivering regolith from the lunar excavator to the production plant is approximately a few hundred meters because the excavator would typically operate this distance away from the production plant; otherwise, it may lead to disturbances in the production plant, such as due to dust.

The conveying distance within the production plant is only a few meters. Therefore, in these applications, completely different conveyor systems are required. Research and development are already conducted for conveyor systems for short distances, and first experiments have already been performed, but for greater distances, the development is still in the first stages, and different even unconventional conveyor systems are possible [10].

Beneficiation: Before the raw material is conveyed to the processing plant, the regolith has to be separated and/or beneficiated. Processing operations, regardless if on Earth or other celestial bodies, require a special type of basic 


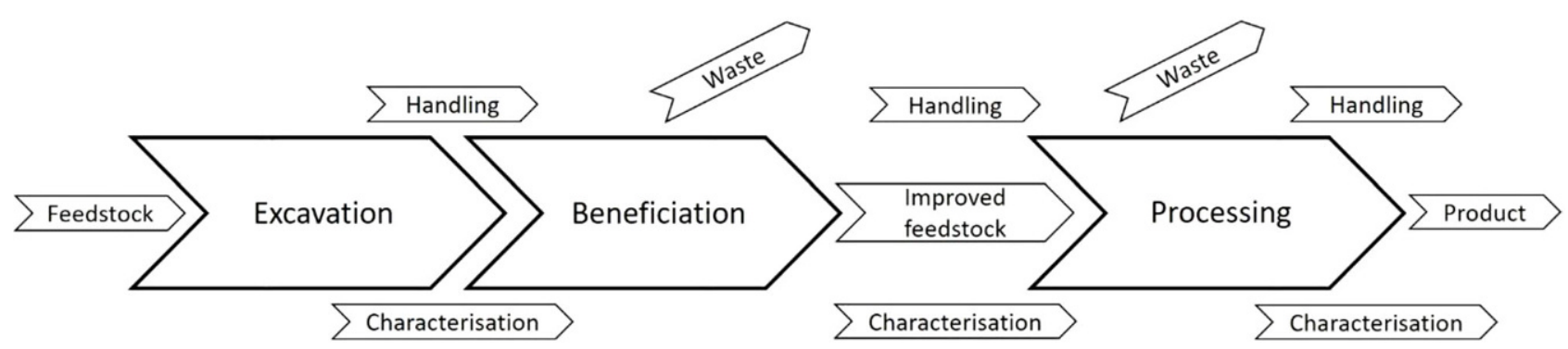

Fig. 4: ISRU Chain [9]

material. Moreover, with a reliable beneficiation process leading to a homogeneous feedstock, mechanical problems in the processing plant will not occur. For further steps, the beneficiation process must include material enrichment and size classification. For instance, the basic material for the hydrogen reduction process using ilmenite has to contain $80-90 \%$ ilmenite. Most of the terrestrial beneficiation technologies use systems based on gravity (like shaking tables) or use much water (such as froth flotation). Yet, these methods are very difficult to apply on the Moon because fluids do not exist in sufficient quantity, and the low gravity leads to problems with gravitation-based methods. For lunar beneficiation applications, magnetic and electrostatic techniques have more potential than, for example, gravityor water-based systems [11].

Electrostatic separation has gained the greatest attention for lunar separation systems. This technology uses the changes in the Coulomb and/or dielectrophoresis forces and manipulates these two forces. Both systems (Coulomb and dielectrophoresis) have already been tested and have proven to be useful. The Coulomb-based technology separates the particles due to their different surface charges. Furthermore, the particles are polarised in a non-uniform electrostatic field, and the dielectrophoresis force is generated. Fig. 5 shows another technique based on the Coulomb force technology called Tribocharching and Free Fall Separation [11].

Fig. 5: Free fall type separator [11]

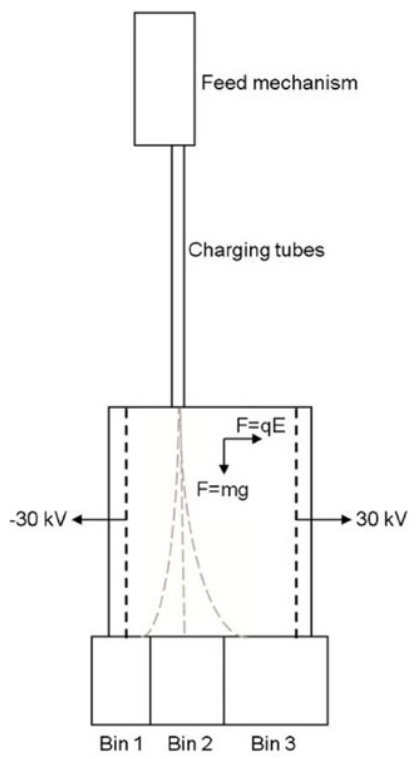

Further, magnetic separation is another beneficiation technology with a high potential for lunar applications. This system is already used in terrestrial applications, for example, to remove ferrous rubbish from other waste. Materials can have three different magnetic behaviours (diamagnetism, ferromagnetism, and paramagnetism). For instance, ilmenite is a paramagnetic material and the magnetic moments react to other magnetic fields [11].

Processing: Oxygen production is an essential aspect of ISRU. In various applications and systems, such as on a lunar human base or to provide oxygen as fuel for rockets, oxygen is significant and is the key for long exploration missions on the Moon and beyond. To illustrate the importance of the availability of oxygen on the Moon, delivering oxygen for a ten-people lunar base from Earth to the Moon would cost between 5 and 9 billion USD. Another limiting factor for transport by rockets from Earth to the Moon is the large proportion of oxygen in the rockets' take-off weight. About $80 \%$ of the total take-off weight of Apollo 11 consisted of oxygen and fuel. If this huge amount of fuel and oxygen could be reduced, the more transportable weight would be available for other equipment. As a result, great efforts have been made by organisations and companies to research and develop several technologies for producing oxygen from the raw materials available on the Moon. There are different technologies for producing oxygen in this regard, such as chemical reduction, pyrolysis, aqueous solvent processing, and electrochemical reduction. Additionally, the output of these technologies depends on the quality of the feedstock, which further depends on the raw material. This aspect highlights the importance of the beneficiation process prior to the processing step. Various processes are described in detail in the following [10].

Hydrogen reduction technology is usually used when the feedstock contains a large proportion of iron ore, such as ilmenite. The working temperature of the process is about $900^{\circ} \mathrm{C}$ and is relatively simple. The chemical equation for this process:

$$
\mathrm{FeTiO}_{3}+\mathrm{H}_{2}=\mathrm{Fe}+\mathrm{TiO}_{2}+\mathrm{H}_{2} \mathrm{O}
$$

Water is a product of this chemical process and is afterwards in a gaseous state. Finally, the water goes further to an electrolysis process. The produced hydrogen goes back to the reduction process. NASA has already developed a reduction reactor called ROxygen, and Lockheed Martin Astronautics has also developed a reactor called PILOT, shown in Fig. 6 [10, 12]. 
Fig. 6: a ROxygen Gen I Reactor, b ROxygen Gen II Reactor cPILOT rotating reactor [12]

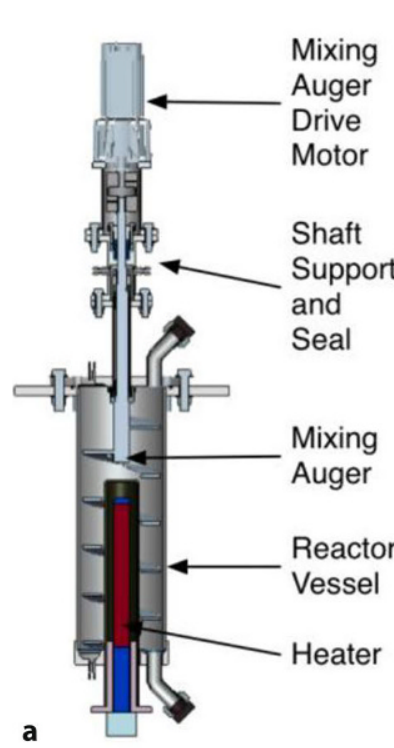

a

Another reduction process possible to produce oxygen on the Moon is called carbothermal reduction. There are some major differences between the hydrogen and the carbothermal reduction process. The carbothermal process works with methane as an educt, which is suitable for several materials contained in the regolith feedstock, such as silicon oxide, and the working temperature is approximately $1600^{\circ} \mathrm{C}$. In addition, higher reduction levels are possible with carbothermal reduction. The chemical equations are as follows:

$$
\begin{aligned}
& \mathrm{FeTiO}_{3}+\mathrm{CH}_{4}=\mathrm{Fe}+\mathrm{TiO}_{2}+\mathrm{CO}+2 \mathrm{H}_{2} \\
& \mathrm{MgSiO}_{3}+2 \mathrm{CH}_{4}=\mathrm{Si}+\mathrm{MgO}+2 \mathrm{CO}+4 \mathrm{H}_{2} \\
& \mathrm{CaSiO}_{3}+2 \mathrm{CH}_{4}=\mathrm{Si}+\mathrm{CaO}+2 \mathrm{CO}+4 \mathrm{H}_{2}
\end{aligned}
$$

In the next step, a nickel catalyst is used for water production:

$$
\mathrm{CO}+3 \mathrm{H}_{2}=\mathrm{CH}_{4}+\mathrm{H}_{2} \mathrm{O}
$$

As in the hydrogen reduction process, water finally passes to electrolysis. This process has been declared by ESA as its preferred method for the production of oxygen [10].

In the vapour phase pyrolysis, also a bulk feedstock of regolith is appropriate for this process. A working temperature of above $2000^{\circ} \mathrm{C}$ is required to decompose the strong bonds between the metal oxides. The chemical equations are as follows:

$$
\begin{aligned}
& \mathrm{FeTiO}=\mathrm{Fe}+\mathrm{TiO}_{2}+0.5 \mathrm{O}_{2} \\
& \mathrm{MgSiO}_{3}=\mathrm{SiO}+\mathrm{MgO}+0.5 \mathrm{O}_{2} \\
& \mathrm{CaSiO}_{3}=\mathrm{SiO}+\mathrm{CaO}+0.5 \mathrm{O}_{2}
\end{aligned}
$$

Maximum oxygen yields of about $50 \%$ can be achieved if various process factors are well adjusted, for instance, temperature and duration [10].

In polar regions of the Moon, especially in deep craters, NASA's LCROSS mission detected water ice in accept-

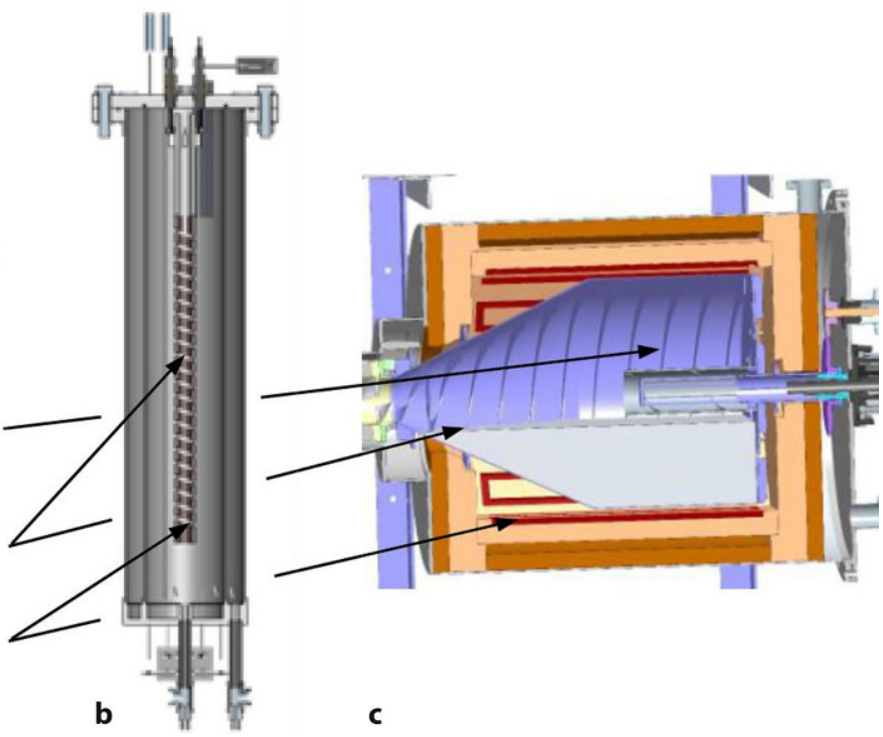

able quantities. Since water is one of the most important elements for humankind, water ice could become a 'gamechanger' for life on the Moon. Although water ice opens many possibilities, many problems are still ahead. For example, ice mining operations are energy-consuming and technically problematic due to the low temperatures of down to $-230^{\circ} \mathrm{C}$, the rough environment, and the mountainous and challenging terrain [10].

\section{Mining Systems}

As mentioned above, the regolith covers most of the Moon's surface. This soft surface would make heavy machines sink in. Of course, the low gravity, too, has a great influence on the degradation behaviour. For example, if a back-loader carries out a digging operation, it would push itself away from the ground due to the low attraction instead of digging a hole. Also the cohesion and the sharp form of the agglutinates affect the dismantling. Because of the high cohesion, blockages can easily occur, and the sharp grain forms lead to high wear of the different components.

But there are still a few functional principles, which are possible for excavation. Some of them are mentioned in the following paragraphs.

Hurling excavator: Using the function of a sweeper, with two brush heads or paddle wheels. The biggest advantage is the simple structure, but unfortunately, there are more disadvantages-for instance, the high rotational speed, which increases wear and dust generation. Also the impacts of harder materials can destroy the paddle wheels.

Bucket elevator/bucket chain excavator: These concepts can be used for scraping material off the lunar surface. With its high mass flow rate and robust structure, it is a promising solution. But there are also some disadvantages, like the risk of clogging or the high dead weight. But with an optimised design, these aspects can be considered. 
Fig. 7: Sketch of the bucket elevator with bridge

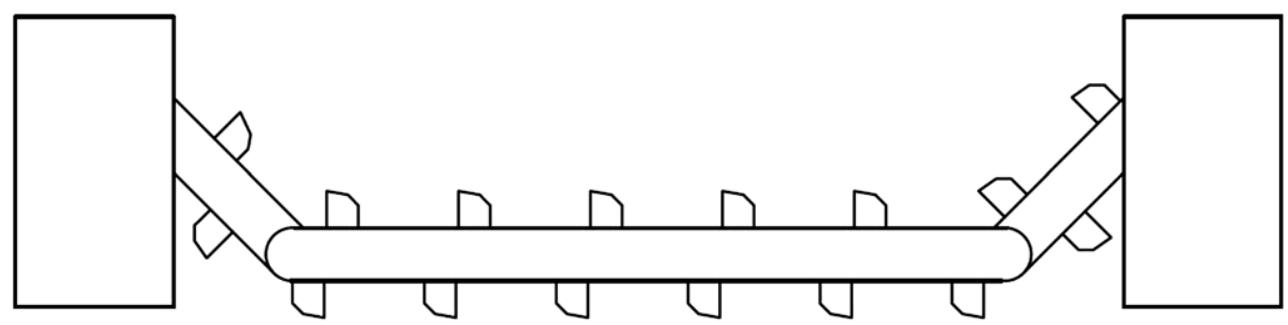

Fig. 8: Principle degradation areas

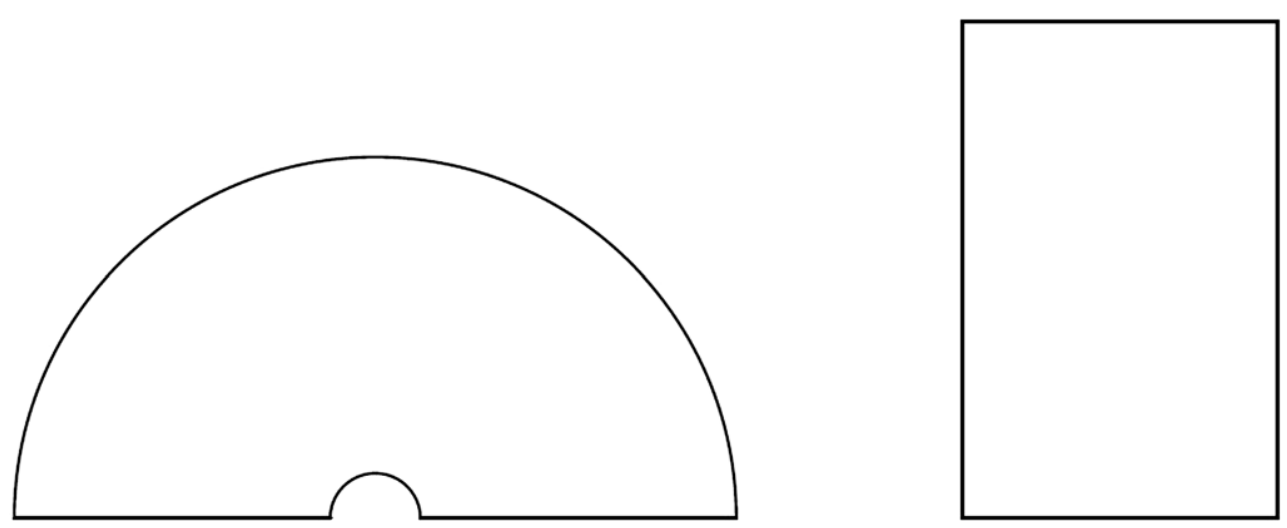

Pneumatic excavator: Picking up with the help of pneumatics would have a huge potential as no moving parts are outside the plant and a lower energy consumption is required. But the biggest problem is the tightness of the system and the use of a transportation gas or fluid. Because there is no possibility of maintenance, this concept is not applicable right now.

There are several other possibilities which are discussed in detail in the master thesis on which this contribution is based on.

After a selection process, the bucket chain excavator proved to be a promising concept. There are two chances of using this concept, namely either as a bucket chain excavator with a boom or as a bucket chain excavator with a bridge. This bucket chain system is in principle somehow similar to systems used on Earth, but details need to be adjusted for use on the Moon's surface. The concept with the bridge has been chosen because of the resulting higher mass flow and the bigger removal area. The course of the buckets of such a system can be seen in Fig. 7 .

A horizontal bucket excavator is accordingly used, which scrapes the material from the surface. Due to the articulated mounting of the main beam on the two adjustable side beams, the excavation depth can be slightly varied. Because of this adjustability, it is also possible to excavate in inclined positions. The length of the main bridge component is estimated at about three to four meters. Due to this structure, one side of the bridge can be fixed, and the other one is doing a semicircular degradation. This is advantageous to the conveying system, which can then stay in the same place during the whole excavation process. There is also the possibility of mining in combination with a linear movement. The possible degradation areas can be seen in Fig. 8.
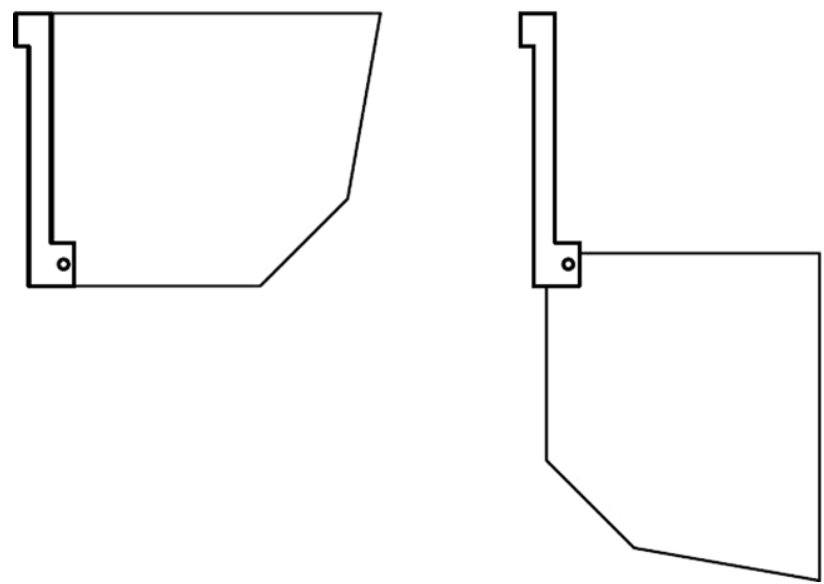

Fig. 9: Sketch of the notching mechanism

Another special feature of this concept is the notching of the bucket during the vertical conveying segment. Fig. 9 is a principle sketch from the notching mechanism, seen from the side. After the release, the bucket swings down until it hits a plate. This results in an impulse-like complete emptying, where the material is thrown off in batches. This discharge variant has been chosen because a gravity discharge is not quite easily possible due to the course of the buckets and a gravity discharge would also take quite long. The material is then discharged into a chute, which transfers the regolith to the conveying unit.

The optimisation of the bucket shape and function is an important step regarding mass flow and good discharge properties. Therefore, DEM (Discrete Element Method) simulations are applied in this area. First tests have already shown that the speed of the bucket must not be too high, which is why the decision was based on a bucket 
speed of about $0.3 \mathrm{~m} / \mathrm{s}$. A mining volume of three cubicdecimeters per bucket is targeted.

The ideal blade spacing still has to be found out accordingly. This is directly related to the speed of rotation or the travel speed during mining.

\section{Conveying System}

As described in Sect. 5, two different types of conveyor systems are necessary on the Moon. The master's thesis deals with the development of a conveyor system for longer distances (e.g. some 100 meters; directly after the excavation unit). On Earth, many different types of conveyor systems are already in use, but on the Moon, there are some challenging requirements. First of all, many conventional conveyors have a fixed conveying path, such as the belt conveyor. Due to the excavation of the uppermost centimetres of the lunar surface and the limited size of the excavation system, the excavation system often changes its location. Therefore, the implementation of a conveyor system with a fixed conveying path is difficult and problematic to realise. Moreover, the conveying system has to operate autonomously after arrival on the Moon. This means that there is no astronaut on the Moon who can mount different parts on the conveyor or do maintenance of the system. In the course of this section, certain concepts are analysed in principle, and in the end, a concept with promising potential is described in detail.

Up first, rovers would come to mind for these unique requirements because of their high mobility/flexibility, easily scalable, and comparable as a known solution with several advantages. Yet, there are some essential drawbacks: limited range due to energy storage, relatively low speed, and maintenance problems because of the abrasive lunar dust, especially at the wheels. Many rovers, which are connected to a chain-like system, can principally form a continuous conveying system. Furthermore, instead of dump trucks, rovers with a belt conveyor (or similar) on top can form a flexible conveying path. These systems have at least one big disadvantage, which lies in the enormous weight of the total system. Fig. 10 shows a possible solution of a lunar rover.

Tubular drag, scraper, and screw conveyors are more suitable for short distances than for longer conveying dis-

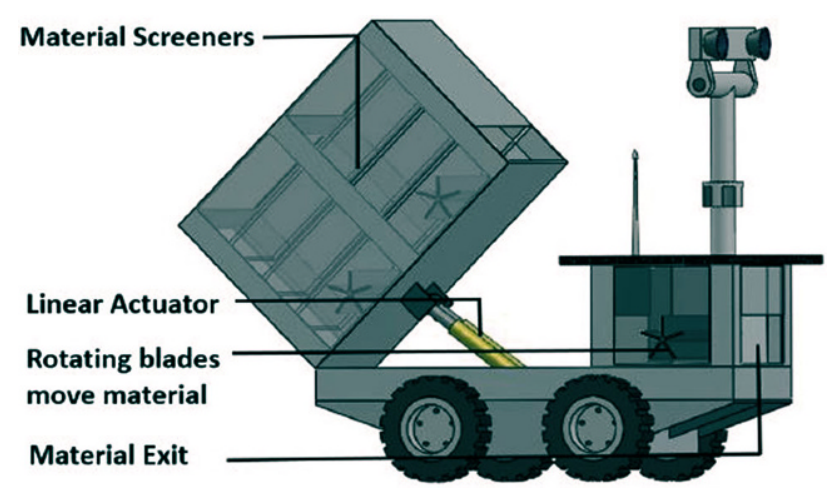

Fig. 10: Extraterrestrial Rover [13] tances, but they may have some benefits: they are continuous conveying systems and are easy to automate. Nevertheless, there are some crucial disadvantages. Very high friction and wear of carrier parts as well as many moving mechanical parts also require a high maintenance effort. They also have low flexibility and are high-weight solutions. Similarly, vibrating conveyors have almost the same advantages and disadvantages. As with the other conveyors, they cover an insufficient conveying range, so they fit better for material handling within the processing plant.

Another possible solution would be a railway system. Such a railway on the Moon would not look like a railway on Earth. The rails would be on supports so that the rails are approximately half of a meter above the lunar surface. Thereby the rails are not influenced negatively and have no contact with the lunar soil, which leads to less wear. Moreover, a semi-flexible conveying path could be realised with mobile supports. An additional advantage is the high amount of payload capacity. Despite the promising advantages, there are some drawbacks: some infrastructure is necessary and may be too heavy for transportation to the Moon, and, especially for longer conveying distances, an implementation of a circular conveying path would be difficult, and also maintenance problems would occur.

Further, Maglev transportation could be an opportunity. On the one hand, magnetic levitation can reach high transportation velocities and has a high payload capacity with a moderate maintenance effort. But on the other hand, it is complex, has a heavy structure, inefficient for small workload, and has a massive energy consumption.

Likewise, a ropeway system is another possibility. Based on mobile supports, similar to the railway, a ropeway is, in general, a simple system. It also has a high payload capacity, is relatively energy efficient, is above the lunar surface, and therefore fewer maintenance problems would occur. The negative aspects of this system are almost the same as with the railway: it would be too heavy to be delivered from Earth to the Moon, and a lot of initial infrastructure would be required.

Alternatively, pneumatic conveying is also a feasible system. Without a doubt, the hard vacuum on the lunar surface is the greatest drawback. Besides, there are other disadvantages, too: an enormous amount of infrastructure is required, including complex filter systems. If leakage occurs, the system will not work anymore, and the temperature fluctuations will lead to completely different properties of the conveying gas (i.e. expansion); yet, there are a few essential advantages: positive aspects regarding friction/wear due to conveyed regolith in the interior of the pipe and no external mechanical parts, which can be damaged by lunar dust.

One other system which would work on the Moon is electromagnetic conveying (Fig. 11). This system contains many coaxial wound coils located at a certain distance to each other. The interconnected coils thus form a series of linearly arranged tube sections. Through electronic impulses at certain times in the coils, a force is induced which transports the regolith from one coil to the next one. The major benefits of this system are that dust is prevented while conveying, no maintenance, no friction and wear oc- 
Fig. 11: Electromagnetic Conveyor [2]

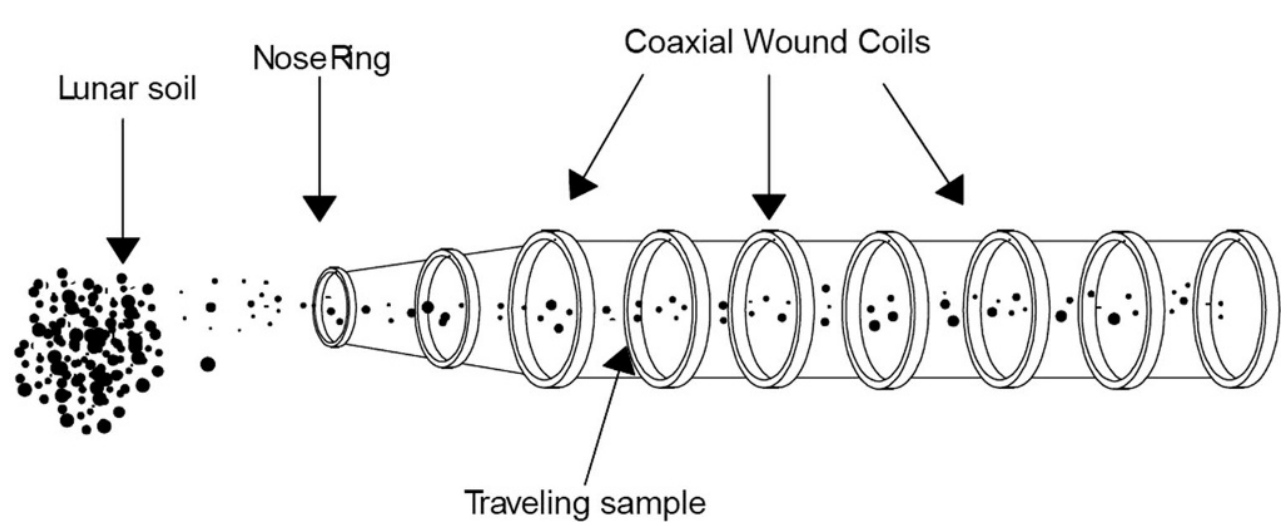

cur, and no mechanical moving parts are required. A positive effect is also that the material will not block the conveyor in case of a full stop during operation. Although there are many advantages, one significant disadvantage causes several problems: Not every content of bulk material is transportable, and also the relatively high amount of required energy is considerable.

Finally, a system with high potential, as analysed to this date, is ballistic conveying (Fig. 12). Even though ballistic conveying systems seem quite unusual and are used only in a few applications used on Earth, for instance, in a field chopper or in woodchip machines, they have various main advantages. Due to the low gravitational acceleration and the hard vacuum (resulting in no air resistance) on the lunar surface, large conveying distances are feasible. Furthermore, such a system is completely flexible as a mobile design is possible. In contrast to almost all other conveying systems where the cohesion of regolith is a problem, the cohesion effects inside of regolith can be a benefit because it will hold together, especially in mid-air, when a badge of material is thrown over a specific distance. A complex system could be the control unit of the launcher, but technologies have already been developed which can target specific positions over long distances, for example, tanks. They can shoot over long distances while the vehicle is in motion and fire the ammunition accurately at any time.
Because of these advantages, the ballistic conveying system was selected among all conveying concepts for further development in the master's thesis. First of all, it is considered how the launcher (or the throwing unit) will work. Terrestrial ballistic conveying systems often use a blast wheel for material transport. Due to the high abrasiveness of regolith, this solution is not suitable for a lunar ballistic unit. But there are historical solutions dating back to the Middle Ages: there were already promising solutions for this kind of accelerating material, such as the catapult or the ballista. The catapult principle means that the material would be accelerated in a rotational motion, whereas a ballista principle would accelerate in translational motion. The launch angle is easier to adjust using a ballista concept so that this basic idea will be considered for further development.

The launching unit will operate as follows: Regolith is filled in the launch bucket, which is movably guided on a rail-system. The angle of these rails is adjustable. After the filling process and the setting of the firing, the drive will accelerate the launch bucket. The drive can be designed in different ways, such as an electric cylinder or by pretensioning of springs. When the launch bucket reaches the maximum velocity, it is slowed down by a stopping system (such as spring damper or energy-recovering unit). The material is thus thrown out of the launch bucket. The launch bucket itself is then put back in its initial position,

Fig. 12: Ballistic Conveying [2]

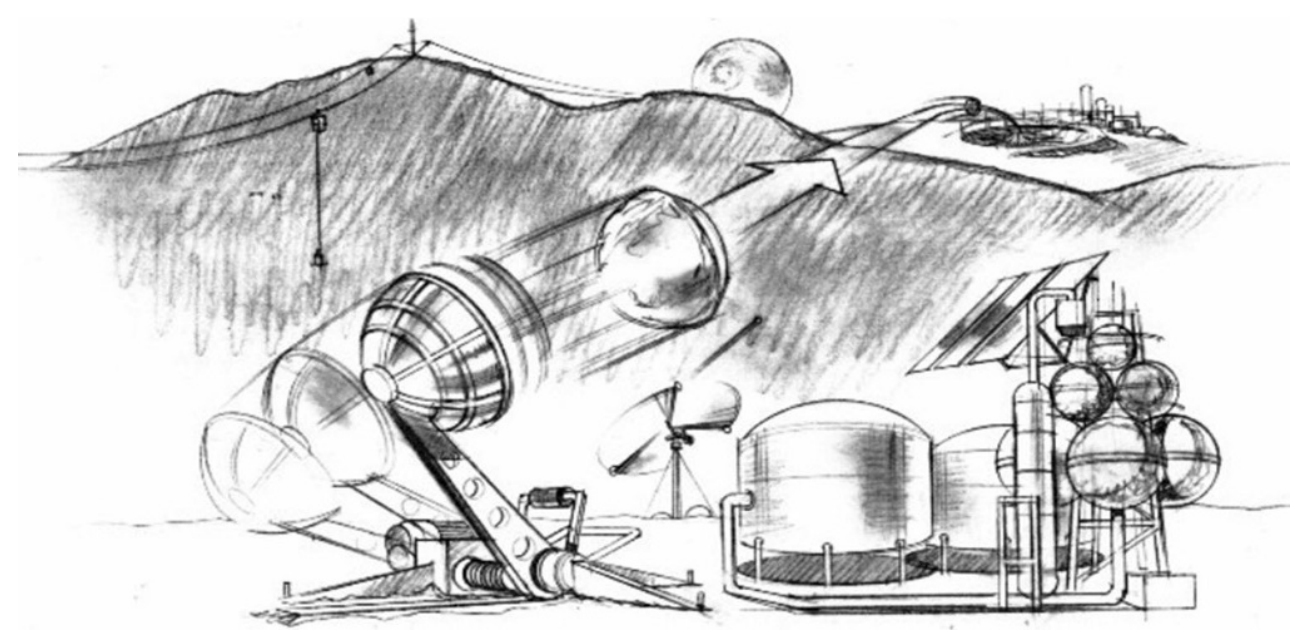


and finally, the filling process of the bucket can start again. As a result, the material can be delivered for hundreds of meters. After the flight phase, the material lands in the collection unit near the processing plant, where it is conveyed to be processed further. Therefore, the collection unit 'catches' the material. Furthermore, a mobile intermediate collection unit, which can be used to lengthen the conveyor distance, is also an idea for further expanding the excavation area and for consequently overcoming larger conveying distances to the processing plant.

\section{Further Processes}

At the moment we have finished the concept development phase for both systems and our results will be published at a later date. Further steps have to be done:

- Development of the transfer point between mining and conveying unit

- Specific concepts for each assembly, especially for machine elements and joints

- Various calculations for each system, for instance, maximum of conveying distance, and required torques and forces of the drives

- Detailed design of each system

- DEM simulations to determine the volume and mass flow of the extracted material, to simulate the flight behaviour of the material, and to define the required torque for the engine of the bucket system

\section{Summary and Outlook}

An independent supply for life and also technological systems, such as energy supply on the Moon, is becoming more and more attractive. For this reason, the ISRU chain has to work without errors and has be tested on Earth. In order for this to be possible, mining and conveying is the first crucial step. Quite creative approaches are necessary to meet the corresponding requirements on the Moon, which are quite different from those on Earth. Several methods for some applications are already being developed, but specific systems for space excavation and conveyance with high performance and effectiveness have not been developed yet. Within this work, a contribution to this major part of the ISRU chain is made, which is probably the initial step for further space exploration projects, such as explorations to Mars and even further.

It is quite conceivable that these systems developed specifically for extraterrestrial use may also be of use here on Earth, whether in combination as total systems or also individually. As a simple illustration of that idea, the throwing unit may be an alternative solution for specific conveying tasks, for example, for overcoming rough terrain (canyons, rivers etc.), which also requires a complex conveying system.

Funding. Open access funding provided by Montanuniversität Leoben.

Open Access This article is licensed under a Creative Commons Attribution 4.0 International License, which permits use, sharing, adaptation, distribution and reproduction in any medium or format, as long as you give appropriate credit to the original author(s) and the source, provide a link to the Creative Commons licence, and indicate if changes were made. The images or other third party material in this article are included in the article's Creative Commons licence, unless indicated otherwise in a credit line to the material. If material is not included in the article's Creative Commons licence and your intended use is not permitted by statutory regulation or exceeds the permitted use, you will need to obtain permission directly from the copyright holder. To view a copy of this licence, visit http://creativecommons.org/licenses/by/4.0/.

\section{References}

1. NASA. Video: What Can You See in the Night Sky This Month? Skywatching Tips from NASA-NASA Solar System Exploration. [November 26, 2020]; Available from: https://solarsystem.nasa.gov/ news/985/video-what-can-you-see-in-the-night-sky-this-monthskywatching-tips-from-nasa/.

2. Schrunk, D. G.: The Moon: Resources, future development, and settlement. 2nd ed. Berlin, Chichester, UK: Springer; Published in association with Praxis Pub; 2008.

3. Torge, W.: Geodäsie. 2nd ed. Berlin, Boston: De Gruyter; 2002.

4. Heiken, G; Vaniman, D.; French, B.M. (eds.): Lunar sourcebook: A user's guide to the moon. Cambridge: Cambridge University Press; 1991.

5. Liu, T.; Wei, C.; Liang, L.; Zhang J., Zhao, Y.: Simulation and Analysis of the Lunar Regolith Sampling Process Based on the Discrete Element Method. Trans. Japan Soc. Aero. S Sci., 57 (2014), no 6, pp 309-16

6. Colwell, J. E.; Batiste, S.; Horányi, M.; Robertson, S.; Sture, S.: Lunar surface: Dust dynamics and regolith mechanics. Rev. Geophys., 45 (2007), no 2

7. Sacksteder, K.; Sanders, G. (eds.): In-Situ Resource Utilization for Lunar and Mars Exploration: Aerospace Research Central; 2007.

8. Hadler, K.; Martin, D. J. P.; Carpenter, J.; Cilliers, J. J.: A Universal Flowsheet And Terminology For In Situ Resource Utilization (ISRU)

9. Just, G. H.; Smith, K.; Joy, K. H.; Roy, M. J.: Parametric review of existing regolith excavation techniques for lunar In Situ Resource Utilisation (ISRU) and recommendations for future excavation experiments. Planetary and Space Science, 2020, 180:104746.

10. Badescu, V.: Moon: Prospective Energy and Material Resources. 1st ed. Berlin, Heidelberg: Springer Berlin Heidelberg; Imprint: Springer, 2012.

11. Rasera, J. N.; Cilliers, J. J.; Lamamy, J. A.; Hadler, K.: The beneficiation of lunar regolith for space resource utilisation: A review. Planetary and Space Science 2020;186:104879.

12. Sanders, G. B., Larson, W. E.: Progress Made in Lunar In Situ Resource Utilization under NASA's Exploration Technology and Development Program. J. Aerosp. Eng., 26 (2013), no 1, pp 5-17

13. Thangavelauthan, J.; Chandra, A.; Jensen, E. (eds): Autonomous Multirobot Technologies for Mars Mining Base Construction and Operation: International Astronautical Federation (IAF); 2019.

Publisher's Note. Springer Nature remains neutral with regard to jurisdictional claims in published maps and institutional affiliations. 